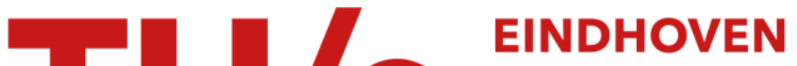 \\ UNIVERSITY OF \\ TECHNOLOGY
}

\section{Low-temperature deposition of TiN by plasma-assisted atomic layer deposition}

Citation for published version (APA):

Heil, S. B. S., Langereis, E., Roozeboom, F., Sanden, van de, M. C. M., \& Kessels, W. M. M. (2006). Lowtemperature deposition of TiN by plasma-assisted atomic layer deposition. Journal of the Electrochemical Society, 153(11), G956-G965. https://doi.org/10.1149/1.2344843

DOI:

10.1149/1.2344843

Document status and date:

Published: 01/01/2006

Document Version:

Publisher's PDF, also known as Version of Record (includes final page, issue and volume numbers)

Please check the document version of this publication:

- A submitted manuscript is the version of the article upon submission and before peer-review. There can be important differences between the submitted version and the official published version of record. People interested in the research are advised to contact the author for the final version of the publication, or visit the $\mathrm{DOI}$ to the publisher's website.

- The final author version and the galley proof are versions of the publication after peer review.

- The final published version features the final layout of the paper including the volume, issue and page numbers.

Link to publication

\section{General rights}

Copyright and moral rights for the publications made accessible in the public portal are retained by the authors and/or other copyright owners and it is a condition of accessing publications that users recognise and abide by the legal requirements associated with these rights.

- Users may download and print one copy of any publication from the public portal for the purpose of private study or research.

- You may not further distribute the material or use it for any profit-making activity or commercial gain

- You may freely distribute the URL identifying the publication in the public portal.

If the publication is distributed under the terms of Article $25 \mathrm{fa}$ of the Dutch Copyright Act, indicated by the "Taverne" license above, please follow below link for the End User Agreement:

www.tue.nl/taverne

Take down policy

If you believe that this document breaches copyright please contact us at:

openaccess@tue.nl

providing details and we will investigate your claim. 


\title{
Low-Temperature Deposition of TiN by Plasma-Assisted Atomic Layer Deposition
}

\author{
S. B. S. Heil, ${ }^{\text {a,* }}$ E. Langereis, ${ }^{a}$ F. Roozeboom, ${ }^{\mathrm{b}}$ M. C. M. van de Sanden, ${ }^{\text {a }}$ and \\ W. M. M. Kessels ${ }^{\mathrm{a}, * * ;, \mathrm{z}}$
}

${ }^{a}$ Department of Applied Physics, Eindhoven University of Technology, $5600 \mathrm{MB}$ Eindhoven, The Netherlands

${ }^{b}$ Philips Research Laboratories, 5656 AA Eindhoven, The Netherlands

\begin{abstract}
Titanium nitride (TiN) films were deposited by a plasma-assisted atomic layer deposition (PA-ALD) process, based on TiCl precursor dosing and remote $\mathrm{H}_{2}-\mathrm{N}_{2}$ plasma exposure, at temperatures ranging from 100 to $400^{\circ} \mathrm{C}$. The plasma, the PA-ALD process, and the resulting TiN material properties were extensively investigated. The plasma was studied by optical emission spectroscopy and Langmuir probe, revealing an ion density of $10^{9} \mathrm{~cm}^{-3}$ and an electron temperature of $3.5 \mathrm{eV}$ just above the substrate. Under floating conditions there is thus a considerable ion flux towards the substrate per ALD cycle with a typical ion energy of $\sim 15 \mathrm{eV}$. TiN film growth was studied by in situ spectroscopic ellipsometry, revealing self-limiting surface reactions for the complete temperature range. At $100^{\circ} \mathrm{C}$ the growth rate of $0.3 \AA /$ cycle was found to be significantly lower than the growth rate of $0.6 \AA /$ cycle at $400^{\circ} \mathrm{C}$. The stoichiometry of the films varied with the plasma exposure time, while the $\mathrm{Cl}$ content was mostly affected by the deposition temperature $\left(2.1\right.$ atom $\%$ at $100^{\circ} \mathrm{C}$ to 0.07 atom $\%$ at $\left.400^{\circ} \mathrm{C}\right)$. Resistivities as low as $71 \mu \Omega \mathrm{cm}$ were obtained at a temperature of $400^{\circ} \mathrm{C}$, while at $100^{\circ} \mathrm{C}$ a fair resistivity of $209 \mu \Omega \mathrm{cm}$ was reached. These results show that PA-ALD with $\mathrm{TiCl}_{4}$ and $\mathrm{H}_{2}-\mathrm{N}_{2}$ plasma is well suited for low-temperature deposition of high-quality TiN films. (C) 2006 The Electrochemical Society. [DOI: 10.1149/1.2344843] All rights reserved.
\end{abstract}

Manuscript submitted January 27, 2006; revised manuscript received June 6, 2006. Available electronically September $12,2006$.

The unique material properties of titanium nitride (TiN) such as high thermal stability, chemical inertness, and low electrical resistivity make it a widely studied material in the semiconductor industry. TiN has been studied for applications such as copper diffusion barrier in interconnect technology, ${ }^{1-3}$ as protective layer during tungsten chemical vapor deposition (CVD) in contact holes, and as gate metal for dynamic random access memory (DRAM) capacitor devices, and complementary metal-oxide-semiconductor (CMOS) transistors. ${ }^{4-6}$ At present, some of these applications pose stricter demands on the deposition temperatures, while the requirements on the step coverage keep increasing with the continuous trend towards higher aspect ratio structures with every technology node.

Atomic layer deposition (ALD) is a very promising thin-film process technology to meet these requirements. ALD is a CVD-like process which is based on the alternating exposure of the substrate surface to different deposition precursors. To avoid direct reaction between the precursors as in conventional CVD, the dosing steps in an ALD cycle are intermitted by purge steps. The precursors have a selective reactivity to certain surface groups such that the deposition chemistry is limited to the first monolayer of the substrate surface, resulting in at maximum one atomic layer being deposited per cycle. The chemistry is such that the second precursor is reactive to the surface groups created by the first precursor and vice versa. The selective chemistry at temperatures below the (self-)decomposition temperatures of the precursors, as well as the self-limiting surface reactions during separated precursor steps, allow the ALD deposition process to take place with excellent step coverage and at substrate temperatures of typically $400^{\circ} \mathrm{C}$ or lower.

Currently, for ALD of TiN, the best material properties are obtained using $\mathrm{TiCl}_{4}$ and $\mathrm{NH}_{3}$ as precursors. With this process, lowresistivity films and a perfect step coverage have been obtained in high aspect ratio (10:1) structures at a deposition temperature between 350 and $400^{\circ} \mathrm{C}^{7}$ For lower temperatures, however, the formation of ammonium chloride $\left(\mathrm{NH}_{4} \mathrm{Cl}\right)$ by $\mathrm{HCl}$ and $\mathrm{NH}_{3}$ during the precursor step, which sticks to the surface, is suggested to be the main cause for the inclusion of higher amount of $\mathrm{Cl}$ impurities in the film. ${ }^{8}$ Unfortunately, a high $\mathrm{Cl}$ impurity content is known to deteriorate the long-term reliability of devices. ${ }^{9}$

To enable deposition at low temperatures, the use of plasma pro-

\footnotetext{
* Electrochemical Society Student Member.

** Electrochemical Society Active Member.

${ }^{\mathrm{z}}$ E-mail: w.m.m.kessels@tue.nl
}

duced radical species for halide abstraction in the ALD process provides a good alternative. ${ }^{10}$ In such so-called plasma-assisted ALD (PA-ALD) processes, the use of a plasma has recently been reported to provide films with excellent material properties at deposition temperatures around $400^{\circ} \mathrm{C} .11,12$ For $\mathrm{TiN}$, the investigations have mainly been confined to substrate temperatures between 300 and $400^{\circ} \mathrm{C},{ }^{11,12}$ although some studies have also indicated that a PAALD process should be possible for temperatures down to $100^{\circ} \mathrm{C} \cdot{ }^{13,14}$ Besides the production of radicals, a plasma-based process also has the unique property that the substrate is exposed to a considerable ion flux. The influence of these ions on the film properties has not yet systematically been addressed, although it might be significant, depending on the plasma configuration, i.e., remote or direct, used. Furthermore, the light emitted by the plasma allows for an additional way of studying the ALD process via optical emission spectroscopy.

Although still a metal-halide-based process (MH-ALD), the lowdeposition temperature in PA-ALD allows for a broader range of applications of the TiN films. For example, by depositing below $250^{\circ} \mathrm{C}$ the $\mathrm{CuCl}$ formation and resulting $\mathrm{Cu}$ pitting could be sufficiently suppressed. ${ }^{8}$ When a low $\mathrm{Cl}$ contamination is tolerated, PAALD TiN might, therefore, find applications in rapidly emerging fields such as sensor and microsystem technology as well in the field of $3 \mathrm{D}$ integration of integrated circuits. ${ }^{15,16}$ In $3 \mathrm{D}$ integration passive and active components are integrated in stacked die structures used in so-called "system-in-package" devices. An example of integrated passive components are high-density "trench" capacitors created on chip in an array of holes with high aspect ratios covered by a dielectric gate stack and a metal electrode ${ }^{17}$ Recently, we explored the applicability of a PA-ALD TiN process to deposit a TiN electrode conformally on this feature to replace the current poly-Si electrode material (deposited by LPCVD at $600^{\circ} \mathrm{C}$ ) with the ultimate goal of increasing the capacitance per area and reducing the size of the component. ${ }^{18}$ Furthermore, the TiN film can also serve as a reasonable $\mathrm{Cu}$ diffusion barrier and $\mathrm{Cu}$ plating base for fine throughwafer vias for creating the $3 \mathrm{D}$ interconnects. It is foreseen that for these applications, the TiN films can be deposited in a single process on a wafer with both blind vias and through-wafer vias.

For the implementation of PA-ALD processes, both film quality and conformality are important issues. As a first step, we address in this paper the first issue, i.e., a full investigation of the film properties obtained within the temperature range of 100 to $400^{\circ} \mathrm{C}$ is presented for depositions on flat substrate surfaces. Besides that, also the plasma properties and the PA-ALD process conditions (precur- 
(a)

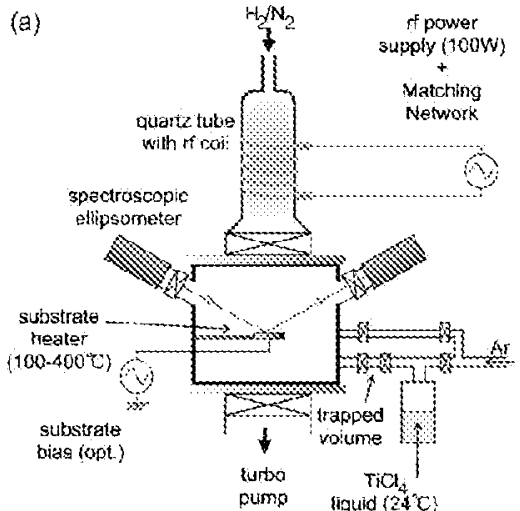

(b)

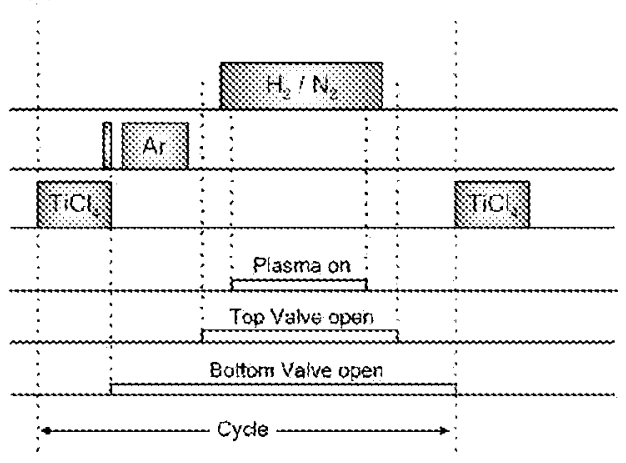

Figure 1. (Color online) Schematic of (a) the PA-ALD reactor and (b) representation of a PA-ALD cycle for TiN deposition. sor dosing, plasma exposure, and purge times) will be addressed in detail. The resulting TiN film properties from the PA-ALD process are compared with those obtained by other ALD processes and the role of the plasma is discussed. The step coverage is addressed when specific applications of the TiN films are investigated and the optimum process conditions have been assessed on the basis of the current work.

\section{Experimental}

$P A-A L D$ reactor. - A schematic overview of the $\mathrm{PA}-\mathrm{ALD}$ reactor is given in Fig. 1. The homebuilt deposition system consists of a remote inductively coupled plasma source (ICP), a stainless-steel deposition chamber, a precursor dosing system, and a pump unit. The plasma source and pump unit are connected to the deposition chamber through gate valves.

The plasma source consists of a multiple-turn copper coil wrapped around a $6 \mathrm{~cm}$ diameter quartz tube. The source is powered by a function generator at $13.56 \mathrm{MHz}$ and a broadband amplifier providing a plasma power of up to $100 \mathrm{~W}$. The impedance is matched to the source by a manual matching unit consisting of two parallel placed vacuum capacitors in a Pi-network configuration. A $\mathrm{H}_{2}-\mathrm{N}_{2}$ gas mixture (>99.999\% purity) with typically a $10: 1$ mixing ratio is fed into the ICP source using leak valves. The plasma source operates at a pressure of typically $7.5 \mathrm{mTorr}$ and the plasma expands through a $100 \mathrm{~mm}$ heated gate valve into the deposition chamber.

Substrates are loaded on a stainless-steel substrate holder present at a distance of $30 \mathrm{~cm}$ from the plasma source. The temperature of the $2 \mathrm{in}$. diameter substrate holder is actively controlled by a resistive heater and a thermocouple. A clamping ring is positioned on top of the substrate to improve the thermal contact with the substrate holder. The substrate holder is electrically insulated to allow lowvoltage substrate biasing.

$\mathrm{TiCl}_{4}$ precursor (Sigma-Aldrich, $\geq 99.0 \%$ purity) is evaporated at room temperature from a bubbler containing liquid $\mathrm{TiCl}_{4}$ and trapped in a fixed volume $\left(0.25 \mathrm{~cm}^{3}\right)$ in between two gas valves. The $\mathrm{TiCl}_{4}$ is subsequently injected into the chamber by releasing this trapped volume into the chamber, resulting in a working pressure in the chamber of typically $2.5 \mathrm{mTorr}$. During the precursor step the gate valves between the chamber and the pump and between the chamber and the plasma source are closed. The latter prevents TiN deposition in the plasma source.

The chamber is pumped by a combination of a turbo molecular pump $(250 \mathrm{l} / \mathrm{s})$ and a rotary pump $\left(5 \mathrm{~m}^{3} / \mathrm{h}\right)$. A chamber base pressure of $\sim 10^{-6}$ Torr is reached by overnight pumping. The turbo molecular pump is continuously purged with $\mathrm{N}_{2}$ to prevent severe corrosion by the precursor and reaction by-products such as $\mathrm{HCl}$. To reduce precursor condensation, the chamber walls, the gate valves, the precursor supply line, and the exhaust line from the turbo pump to the backing pump are all heated up to a temperature of $\sim 70^{\circ} \mathrm{C}$.
The PA-ALD process is fully automated using National Instruments compact Fieldpoint programmable automation controllers (PACs) and National Instruments Labview software. The PA-ALD process cycle used for TiN deposition is shown in Fig. 1b. Starting with all gate valves closed, the substrate is exposed to $\mathrm{TiCl}_{4}$ by releasing the trapped volume into the reactor. The excess amount of precursor is diluted with Ar just before opening the valve to the pumps. Afterward, an additional purge with Ar followed by another pump-down is implemented to effectively pump out the $\mathrm{TiCl}_{4}$ and the reaction products. The valve to the plasma source is opened and the flow of $\mathrm{H}_{2}$ and $\mathrm{N}_{2}$ is started. Once the pressure is stabilized the source is switched on and the substrate is exposed to the plasma. This is followed by a pump-down of the reactor to base pressure in preparation of the next PA-ALD cycle. An overview of process conditions are listed in Table I including the typical base values and the range of the parameters studied.

The setup is equipped with several view ports for in situ studies such as spectroscopic ellipsometry to monitor film growth, and optical emission spectroscopy and laser spectroscopy to study the plasma species. During deposition the view ports are protected by gate valves ( $25 \mathrm{~mm}$ diameter). Furthermore, other plasma characterization tools such as a Langmuir probe for electron and ion density and electron temperature measurements and mass spectrometry for studying precursor species and reaction products can be fitted to the reactor.

Plasma diagnostics. - In the present work the plasma was studied by optical emission spectroscopy (OES) using an Ocean Optics USB2000 spectrometer with a wavelength detection range of $250-870 \mathrm{~nm}$ and a resolution of approximately $1 \mathrm{~nm}$. The light emission from the plasma was measured both at the plasma source region as well as downstream near the substrate holder. At the plasma source the emission was collected by an optical fiber connected to the spectrometer. To image the emission coming from just above the substrate holder on the entrance of the optical fiber, a 1 in.

\footnotetext{
Table I. Typical operating settings for PA-ALD of TiN films and the range in which the settings were varied during the experiments.
}

\begin{tabular}{lcc} 
& Base value & Range studied \\
\hline Precursor pressure (mTorr) & 2.5 & - \\
$\mathrm{H}_{2}$ pressure (mTorr) & 7.5 & $5-25$ \\
Ratio $\mathrm{N}_{2} / \mathrm{H}_{2}$ & 0.1 & $0-1$ \\
$\mathrm{RF}$ plasma power $(\mathrm{W})$ & 100 & $60-100$ \\
Deposition temperature $\left({ }^{\circ} \mathrm{C}\right)$ & 400 & $100-400$ \\
Precursor dosing (s) & 5 & $1-15$ \\
Plasma exposure (s) & 15 & $2-120$ \\
Purge (s) & 5 & $0-60$
\end{tabular}


diameter, $f=16 \mathrm{~cm}$ focal length lens was used in $2 f-2 f$ configuration. Spectra were taken at different plasma powers, pressures, and $\mathrm{H}_{2}-\mathrm{N}_{2}$ mixture ratios. Typical integration times were $20 \mathrm{~ms}$ for the emission from the plasma source and $200 \mathrm{~ms}$ for the downstream region.

Langmuir probe measurements were carried out simultaneously with the OES measurements at a position just above the substrate holder. The homebuilt double-Langmuir probe consists of two $11 \mathrm{~mm}$ long tungsten wires, approximately $5 \mathrm{~mm}$ apart from each other. The wires were connected to a Keithley 2400 Sourcemeter, which served both as voltage source and as current meter. Typically the applied voltage was varied from -50 to $+50 \mathrm{~V}$. From the Langmuir probe data the electron and ion density and the electron temperature were determined using the method described by Peterson and Talbot. ${ }^{19}$

TiN deposition and film characterization.- The TiN films were deposited on p-type Si wafer substrates $(10-30 \Omega \mathrm{cm})$ at deposition temperatures between 100 and $400^{\circ} \mathrm{C}$. Unless mentioned otherwise, the silicon substrates did not undergo additional cleaning steps and were covered with a $1-2 \mathrm{~nm}$ native oxide layer. The film growth was monitored in situ using a J.A. Woollam, Inc. M2000U visible and near-infrared spectroscopic ellipsometer (SE, $0.75-5.0 \mathrm{eV}$ ) mounted on the chamber at a $68^{\circ}$ angle of incidence with respect to the substrate normal. After every ten completed ALD cycles SE data were acquired by averaging over 500 complete SE spectra. The measurement time was approximately $1 \mathrm{~min}$. The SE data were analyzed by an optical two-layer model in which the dielectric function of TiN was parametrized by the Drude-Lorentz formalism. ${ }^{20}$ Besides yielding information on thickness, the SE analysis also gave insight into material properties such as the electrical resistivity. The method for analysis of the SE data is discussed extensively in separate publications. ${ }^{21,22}$

The film composition was determined by Rutherford backscattering spectrometry (RBS) for the $\mathrm{Ti}, \mathrm{N}, \mathrm{Cl}$, and $\mathrm{O}$ content. Elastic recoil detection (ERD) was used for determining the $\mathrm{H}$ content. A $2 \mathrm{MeV}{ }^{4} \mathrm{He}^{+}$beam was targeted at the surface at two different angles $\left(-80^{\circ}\right.$ and $\left.-10^{\circ}\right)$ for every sample to get improved sensitivity for both the heavy and light elements, while it also allowed for depth profiling of the TiN layer. The RBS and ERD data were modeled using the RUMP program. ${ }^{23}$

The microstructure of the films was studied by X-ray diffraction (XRD) using a Philips X'Pert MPD diffractometer equipped with a $\mathrm{Cu} \mathrm{K} \alpha$ source (1.54 $\AA$ radiation). To reduce the measurement time a Philips X'Celerator detector was used and to increase the surface sensitivity the measurements were performed under grazing angle of incidence. For thickness and mass density determination X-ray reflectometry measurements were performed on a Bruker D8 Advance $\mathrm{X}$-ray diffractometer.

The surface roughness of the TiN film was determined by atomic force microscopy (AFM) using an NT-MDT Solver P47 SPM in noncontact mode using NSG11 TiN covered cantilevers with curvatures below $10 \mathrm{~nm}$. Two scan sizes were used, $1 \times 1$ and 2 $\times 2 \mu \mathrm{m}^{2}$, with 512 sample points in both $x$ and $y$ directions and a scan velocity of $1 \mathrm{~Hz}$. From the scans the rms roughness was extracted by determining the saturation value of the rms roughness with increasing scanned area size.

Ex situ resistivity measurements were carried out at room temperature using a Signatone four-point probe in combination with a Keithley 2400 Sourcemeter acting both as current source and as a voltage meter. The resistivity was determined from the slope of the $I-V$ curve.

Plasma studies.- In the plasma, $\mathrm{H}$ and $\mathrm{N}$ radicals, as well as other reactive species such as excited $\mathrm{N}_{2}$ and possibly $\mathrm{NH}_{x}$ radicals, are created that can contribute to the surface chemistry. While generally not abundant, electrons and ions are also present and the subsequent surface ion bombardment, which is caused by acceleration of the ions toward the substrate caused by the self-bias voltage over the plasma sheath, can provide additional energy for surface reactions to take place. It can lead to substrate modification, but can also contribute to improving the film density. An investigation of the plasma characteristics is therefore imperative. Both in the source as well as in the downstream deposition region, the emission of the plasma is studied using OES. The electrical properties of the plasma in the downstream region have been studied by Langmuir probe measurements.

Although the information obtained from OES is limited because it relies on excitation processes and radiative transitions, it can give qualitative insight into the (radical) species produced in the plasma and their relative densities under different plasma settings. Emission spectra were measured of a $\mathrm{H}_{2}$ plasma, a $\mathrm{H}_{2}-\mathrm{N}_{2}$ (10:1) mixture plasma, and a $\mathrm{H}_{2}-\mathrm{N}_{2}$ (1:1) mixture plasma at the position of the plasma source (see Fig. 2a). In the hydrogen plasma the atomic hydrogen emission from the Balmer series, $\mathrm{H}_{\alpha}(656.5 \mathrm{~nm})$ and $\mathrm{H}_{3}$ $(485.6 \mathrm{~nm})$, indicates the presence of $\mathrm{H}$ radicals. Molecular hydrogen emission from the $d^{3} \Pi_{u} \rightarrow a^{3} \Sigma_{g}^{+}$transition, the so-called Fulcher bands $(590-640 \mathrm{~nm})$, is observed indicating excited $\mathrm{H}_{2}$. In the $\mathrm{H}_{2}-\mathrm{N}_{2}$ mixture plasmas, the $\mathrm{N}_{2}$ emission from the first positive system $B^{3} \Pi \rightarrow A^{3} \Pi(500-1050 \mathrm{~nm})$ and second positive system $C^{3} \Pi \rightarrow B^{3} \Pi(280-500 \mathrm{~nm})$ is observed. The excitation of $\mathrm{N}$, however, depends mainly on collisions with electrons and due to the high excitation energy involved, $\mathrm{N}$ emission is therefore normally not observed. But this does not exclude the possibility that a large amount of $\mathrm{N}$ radicals can still be present. The $\mathrm{N}_{2}$ emission becomes clearly dominant when adding more $\mathrm{N}_{2}$. The absolute intensity of the $\mathrm{H}$ emission appears to become lower with increasing $\mathrm{H}_{2}: \mathrm{N}_{2}$ ratio.

In Fig. $2 b$ a comparison is made between the emission coming from the plasma source and the emission in the downstream region at the position of the substrate holder for a $(10: 1) \mathrm{H}_{2}-\mathrm{N}_{2}$ mixture. Apparently emission is still observed at a distance of $30 \mathrm{~cm}$ from the plasma source, although the intensity has clearly diminished. It can be seen clearly that the $\mathrm{N}_{2}$ emission becomes relatively more dominant in the spectrum downstream compared to the Balmer lines. Recombination of $\mathrm{H}$ at the chamber surfaces can be a possible cause for this. Because the relative intensity of the $\mathrm{H}_{\alpha}$ and $\mathrm{H}_{\beta}$ lines does not change, we can assume that the electron temperature remains roughly the same as the excitation of hydrogen takes mainly place by electron collisions from the ground state.

To monitor the diffusion of the plasma from the source, the absolute intensity of several peaks was measured downstream in a $\mathrm{H}_{2}-\mathrm{N}_{2}$ (10:1) mixture plasma for different pressures (see Fig. 2c). For $\mathrm{N}_{2}$ the $v^{\prime}-v^{\prime \prime}=5-2(670.4 \mathrm{~nm})$ peak in the first positive system $(B-A)$ and the $v^{\prime}-v^{\prime \prime}=0-0(337.1 \mathrm{~nm})$ peak for the second positive system $(C-B)$ were monitored. For hydrogen, $\mathrm{H}_{\alpha}$ and $\mathrm{H}_{3}$ were monitored. The intensity decrease with increasing pressure suggests the plasma generation is more confined to the source region. An increase in emission in the source region is observed at higher pressures. Because all peaks have roughly the same rate of decrease, we can assume that the plasma chemistry and composition remain similar when going to higher pressures.

For the $\mathrm{H}_{2}-\mathrm{N}_{2}(10: 1)$ mixture plasma, which is used in most of the depositions reported, an electron and ion density of $\sim 10^{9} \mathrm{~cm}^{-3}$ was measured for various pressures and plasma powers just above the substrate holder, as shown in Fig. 3a. Despite the remote character of the plasma, this is a considerable electron density in the downstream region which is caused by the low operating pressure. The decrease in electron density at higher pressures again confirms that the plasma is more confined to the source region and diffuses less downstream, as also indicated by the decrease in optical emission intensity. Using the dimensions of the probe we estimated the ion flux towards the substrate, under the typical plasma conditions used for deposition, to be $\sim 2.5 \times 10^{14} \mathrm{~cm}^{-2} \mathrm{~s}^{-1}$. When integrated over the total plasma exposure time the number of ions arriving at 

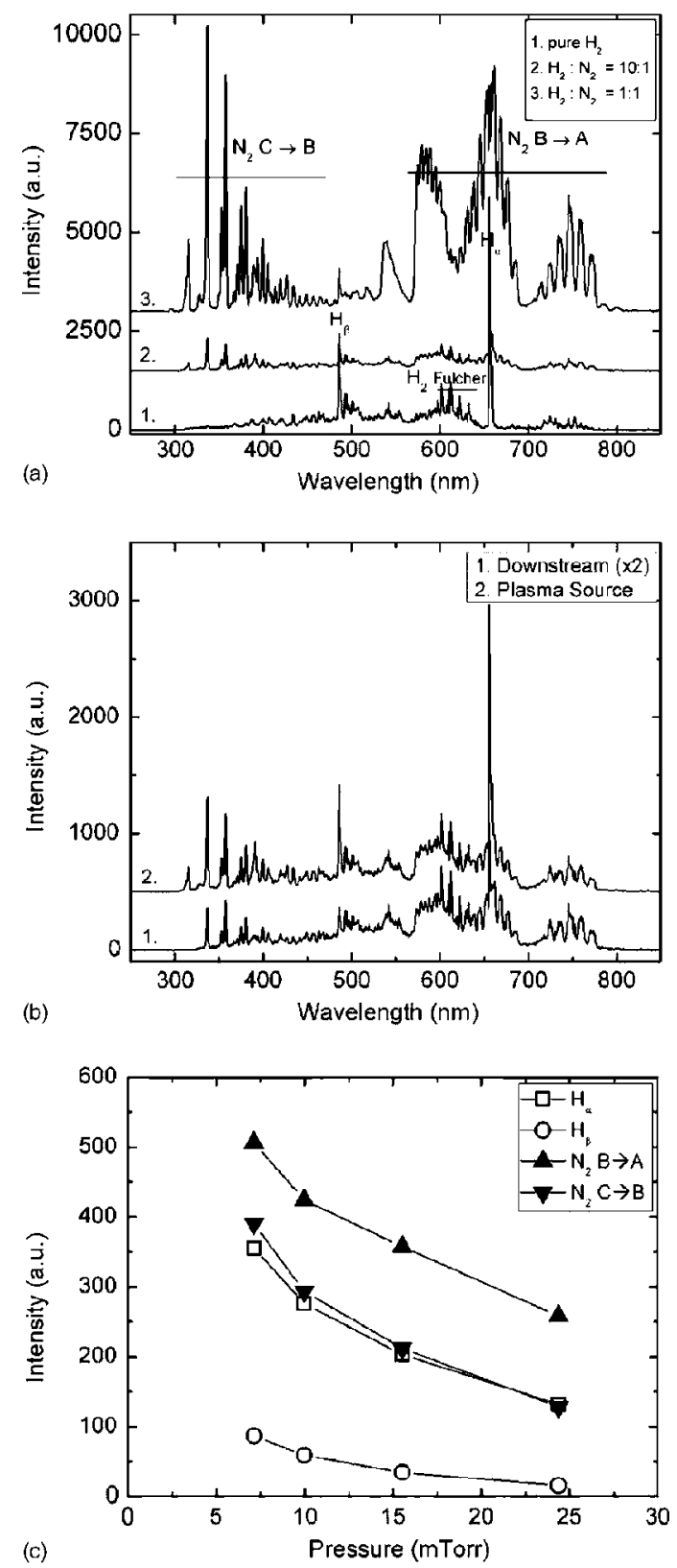

Figure 2. (a) Emission spectra recorded in (a) the plasma source region for a plasma generated in pure $\mathrm{H}_{2}$, a $\mathrm{H}_{2}-\mathrm{N}_{2}(10: 1)$ mixture, and a $\mathrm{H}_{2}-\mathrm{N}_{2}(1: 1)$ mixture. (b) Spectra recorded in the plasma source and downstream region near the substrate holder for a $\mathrm{H}_{2}: \mathrm{N}_{2}$ ratio of $10: 1$. The spectrum in the downstream region is multiplied by a factor of 2 and the spectra are shifted vertically for clarity. (c) Trends of selected peaks as a function of the pressure in the downstream region for a plasma of a 1:1 $\mathrm{N}_{2}-\mathrm{H}_{2}$ mixture. The $\mathrm{H}_{2}$ partial pressure is $11 \mathrm{mTorr}$.

the surface is thus of similar magnitude to the number of deposited molecules, and therefore their contribution to the deposition process can be significant.

The electron temperature ranges from $\sim 3.7$ to $2.7 \mathrm{eV}$ and decreases with increasing pressure as typically expected from the reduced loss of electrons and ions by diffusion (see Fig. 3b). At the typical operating pressure of 7.5 mTorr the electron temperature is $3.5 \mathrm{eV}$. This high electron temperature has the important conse-
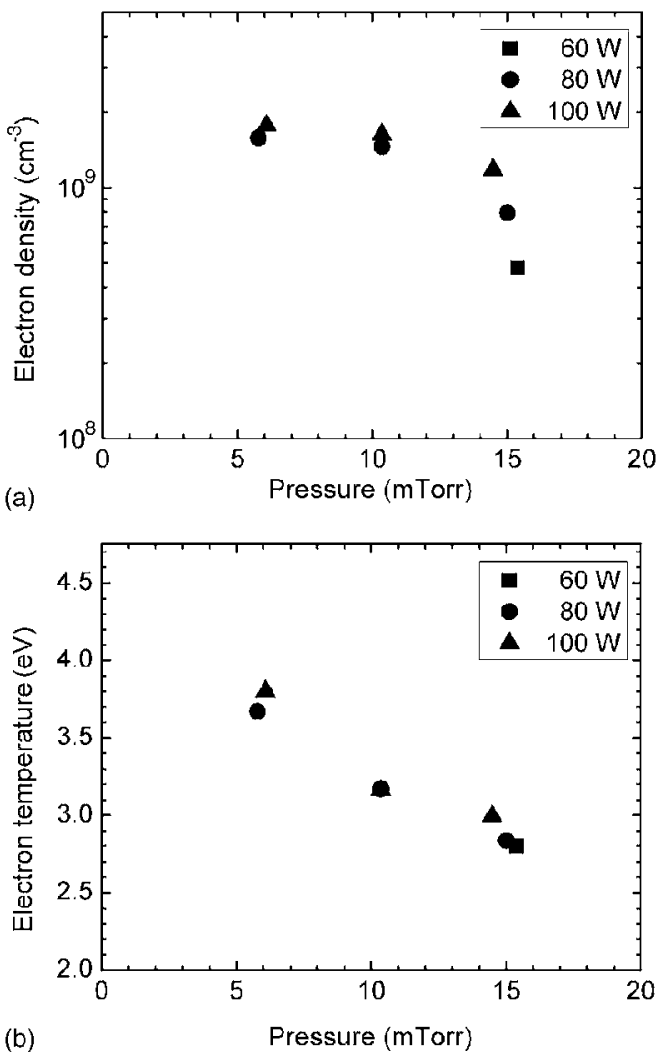

Figure 3. The (a) electron density and (b) electron temperature as a function of pressure for various plasma powers in a $\mathrm{H}_{2}-\mathrm{N}_{2}(10: 1)$ mixture plasma.

quence that the plasma in the downstream region can still be considered as an active plasma and not just as an afterglow. In this active plasma electron-induced ionization and dissociation reactions still take place, as also suggested by the fact that the downstream zone still yields plasma emission of highly excited species such as $\mathrm{H}_{\alpha}$.

From the electron temperature the resulting ion bombardment energy under these low-pressure conditions (i.e., no collisions in the plasma sheath) can be estimated using ${ }^{24}$

$$
E_{\mathrm{ion}} \approx\left|V_{p}-V_{f}\right| \approx \frac{T_{e}}{2}\left(1+\ln \left(\frac{m_{\mathrm{ion}}}{2 \pi m_{e}}\right)\right)
$$

with $V_{p}$ the plasma potential, $V_{f}$ the wall potential, $T_{e}$ the electron temperature in $\mathrm{eV}, m_{\mathrm{ion}}$ the ion mass, and $m_{e}$ the electron mass. For $\mathrm{H}^{+}, \mathrm{N}^{+}$, and $\mathrm{N}_{2}^{+}$ions this leads to typical ion energies of 12,16 , and $18 \mathrm{eV}$, respectively. This means that the average energy of the ions bombarding the sample is roughly $15 \mathrm{eV}$, independent of the source power and slightly dependent on the pressure for the pressure range studied.

TiN film growth and properties.- TiN films were deposited using different process conditions, such as plasma exposure time and deposition temperature. Together with the resulting film properties such as film composition, thickness, and resistivity, these process conditions are summarized in Table II. First we address the variation of the PA-ALD process parameters and their effect on film growth. Second, the elemental composition of the films is presented. Finally, the structural and electrical properties at different film thicknesses and deposition conditions is addressed.

Variation of PA-ALD process parameters: Growth rate.- To investigate whether the deposition process exhibits the ALD charac- 


\begin{tabular}{|c|c|c|c|c|c|c|c|c|c|c|}
\hline \multicolumn{3}{|c|}{ Deposition Conditions } & \multicolumn{3}{|c|}{ Film Composition } & \multicolumn{3}{|c|}{ Film Properties } & \multirow[b]{2}{*}{$\begin{array}{l}\text { Roughness } \\
\text { (nm) }\end{array}$} & \multirow[b]{2}{*}{$\begin{array}{c}\text { Density } \\
\left(\mathrm{g} \mathrm{cm}^{-3}\right)\end{array}$} \\
\hline $\begin{array}{l}\text { Temperature } \\
\left({ }^{\circ} \mathrm{C}\right)\end{array}$ & $\begin{array}{l}\text { Plasma } \\
\text { (s) }\end{array}$ & $\begin{array}{l}\text { Dep. rate } \\
\text { ( } \AA \text { /cycle) }\end{array}$ & {$[\mathrm{N}] /[\mathrm{Ti}]$} & $\begin{array}{c}{[\mathrm{Cl}]} \\
\text { (atom \%) }\end{array}$ & $\begin{array}{c}{[\mathrm{O}]} \\
\text { (atom \%) }\end{array}$ & $\begin{array}{c}{[\mathrm{H}]} \\
\text { (atom \%) }\end{array}$ & $\begin{array}{l}\text { Thickness } \\
\text { (nm) }\end{array}$ & $\begin{array}{l}\text { Resistivity } \\
(\mu \Omega \mathrm{cm})\end{array}$ & & \\
\hline \multicolumn{11}{|c|}{ Plasma exposure variation } \\
\hline 400 & 5 & 0.50 & 0.93 & 0.27 & 6.3 & 4 & 21.8 & 174 & - & - \\
\hline 400 & 15 & 0.55 & 1.0 & 0.25 & 1.6 & 4 & 27.1 & 141 & - & - \\
\hline 400 & 60 & 0.61 & 1.15 & 0.2 & 2.5 & 9 & 15.4 & 144 & - & - \\
\hline \multicolumn{11}{|c|}{ Temperature variation } \\
\hline 400 & 15 & 0.62 & 1.0 & 0.26 & 1.7 & - & 13.6 & 141 & 0.5 & - \\
\hline 300 & 15 & 0.36 & 1.09 & 0.42 & 2.8 & - & 10.8 & 142 & 0.2 & - \\
\hline 200 & 15 & 0.27 & 1.04 & 0.96 & 1.4 & - & 8.4 & 213 & 0.1 & - \\
\hline 100 & 15 & 0.26 & 1.0 & 6.7 & 4.4 & - & 7.7 & 604 & 0.1 & - \\
\hline \multicolumn{11}{|c|}{$>45 \mathrm{~nm}$ samples } \\
\hline 400 & 15 & 0.50 & 1.0 & 0.07 & 1.8 & 3 & 65.5 & 71 & 0.4 & 4.8 \\
\hline 100 & 30 & 0.26 & 1.09 & 2.1 & 2.6 & 16 & 48.2 & 209 & 1.8 & 3.9 \\
\hline
\end{tabular}

teristics of self-limiting growth during the dosing steps, we varied three process parameters: the precursor dosing step, the plasma exposure step, and the intermediate purge step. One parameter was varied while the other two were kept constant. The film thickness was monitored in situ by spectroscopic ellipsometry to determine the growth rate.

For the precursor dosing variation the Ar purge time was set to $5 \mathrm{~s}$, the plasma exposure time was set to $30 \mathrm{~s}$, the deposition temperature was $400^{\circ} \mathrm{C}$. The precursor dosing was varied between 1 and $15 \mathrm{~s}$. Figure $4 \mathrm{a}$ shows that the growth rate becomes constant, $\sim 0.6 \AA$ /cycle, for a precursor dosing time longer than $2 \mathrm{~s}$, indicating a complete saturation of the surface by $\mathrm{TiCl}_{4}$.

A similar experiment was done for the plasma exposure time; the precursor dosing was set to $5 \mathrm{~s}$ and the plasma exposure time was varied. The results are shown in Fig. 4b. For plasma exposure times larger than $15 \mathrm{~s}$ the growth rate becomes constant, indicating a saturated removal of the chlorine by the plasma produced radicals. Both experiments indicate this PA-ALD process exhibits the ALD principle of self-limiting growth under these deposition conditions.

We also varied the influence of the Ar purge time to fully exclude CVD-like growth processes that might occur due to the presence of residual $\mathrm{TiCl}_{4}$ during the plasma step. Such processes could increase the growth rate but normally take place at the cost of lower quality films at the substrate temperatures used. The precursor dosing time was set to $5 \mathrm{~s}$ and the plasma exposure time was set to $15 \mathrm{~s}$. As shown in Fig. 4c, the Ar purge time has no influence on the growth rate. This shows that the dilution of the precursor by Ar at the end of the precursor dosing (employed to improve the lifetime of the pumps) is already sufficient to effectively remove $\mathrm{TiCl}_{4}$ from the chamber. In the following experiments, an Ar purge of $5 \mathrm{~s}$ is included in the cycle but, if desired, this step can be omitted to shorten the cycle time.

To investigate whether the deposition process remains true ALD at low-deposition temperatures, the same experiments were also performed at $100^{\circ} \mathrm{C}$. The process exhibited the same properties with a saturated growth rate of $\sim 0.3 \AA$ /cycle. This growth rate is significantly lower than the $\sim 0.6 \AA /$ cycle obtained at $400^{\circ} \mathrm{C}$. When in vestigating the temperature dependence of the growth rate as shown in Fig. 5, it turned out that the growth rate decreased drastically with decreasing temperature, with the largest drop when going from 400 to $300^{\circ} \mathrm{C}$. The growth rate at $400^{\circ} \mathrm{C}$ is relatively high, but comparable high growth rates for thermal and plasma-assisted ALD of TiN have been reported previously. ${ }^{7,25}$

Film composition.- The stoichiometry and composition of the films were studied by RBS, of which a typical spectrum is shown in Fig. 6. For all RBS measurements, it was found that the $\mathrm{N}$ peak in the spectrum was slightly broader than expected on the basis of the width of the Ti peak, which indicates the presence of nitrogen in the underlying substrate. Apparently, during the PA-ALD process of TiN nitrogen is incorporated into the native oxide covered Si substrate, forming a $\sim 2-3 \mathrm{~nm} \mathrm{SiO}_{x} \mathrm{~N}_{y}$ interface layer underneath the TiN film. The nitridation of the substrate takes place during the initial growth in the first $\sim 40$ cycles as revealed by spectroscopic ellipsometry and is addressed in a separate publication. ${ }^{22}$ The double peak of $\mathrm{Cl}$ in the $\mathrm{RBS}$ spectrum indicates a relatively high $\mathrm{Cl}$ concentration on the buried interface between the $\mathrm{TiN}$ and $\mathrm{SiO}_{x} \mathrm{~N}_{y}$ layer and on the top surface. Oxygen was found mostly in the top part of the film. The double-oxygen peak in Fig. 6 is the result of the native oxide covered silicon substrate and the surface oxidation of the TiN.

With this knowledge, a three-stack model was used to determine the TiN film composition from the RBS measurements. The model is shown in the inset in Fig. 6. $\mathrm{A} \mathrm{SiO}_{x} \mathrm{~N}_{y}$ layer is modeled at the buried interface between the Si substrate and the TiN bulk layer, and a $\mathrm{TiO}_{2}$ layer is modeled on the surface of the TiN film. In all three layers $\mathrm{Cl}$ and $\mathrm{O}$ impurities were included. Hydrogen was assumed to be homogeneously distributed throughout the film. The composition of the films listed in Table II and addressed below refers to the middle part of this model, i.e., the TiN bulk layer.

For the plasma exposure time variation, the stoichiometry $([\mathrm{N}] /[\mathrm{Ti}]$ ratio) of the film was found to change from Ti-rich at low plasma exposures $([\mathrm{N}] /[\mathrm{Ti}]=0.93$ at $5 \mathrm{~s})$ to $\mathrm{N}$-rich at long plasma exposures $([\mathrm{N}] /[\mathrm{Ti}]=1.15$ at $60 \mathrm{~s})$. For a plasma exposure time of $15 \mathrm{~s}$, stoichiometric films with a $[\mathrm{N}] /[\mathrm{Ti}]$ ratio of 1.0 were obtained. When increasing the plasma exposure time from $5 \mathrm{~s}$ to $60 \mathrm{~s}$, the $\mathrm{Cl}$ content decreased from 0.3 to 0.2 atom $\%$ and the $\mathrm{H}$ content, measured by elastic recoil detection, increased from 4 to 9 atom $\%$.

The deposition temperature was varied between 100 and $400^{\circ} \mathrm{C}$ for a plasma exposure time of $15 \mathrm{~s}$. The films were found to be somewhat N-rich for deposition temperatures of 200 and $300^{\circ} \mathrm{C}$. More important is the amount of impurities in the films. At a deposition temperature of $100^{\circ} \mathrm{C}$ the $\mathrm{Cl}$ impurity content in the film is as high as $\sim 7$ atom \% (see Fig. 7). This $\mathrm{Cl}$ content drops, however, drastically when going to temperatures above $200^{\circ} \mathrm{C}$. At $400^{\circ} \mathrm{C} \mathrm{a} \mathrm{Cl}$ impurity content of $\sim 0.3$ atom $\%$ is obtained. The $\mathrm{O}$ impurity content of the film is $\sim 2$ atom $\%$ and does not show a clear trend with temperature. The diffusion of oxygen from the ambient into the film is suggested to be the main source for $O$ impurities.

The impurity content of the films was found to depend strongly on the film thickness, and the best results were found in thicker $(>45 \mathrm{~nm})$ films as shown in Table II. These films were deposited onto H-terminated Si substrates, prepared by dipping the substrate in a diluted $\mathrm{HF}$ solution ( $1 \mathrm{~min}$ ) and rinsing it with deionized water. At a substrate temperature of $100^{\circ} \mathrm{C}$, a $\mathrm{Cl}$ content of 2.1 atom $\%$ was 

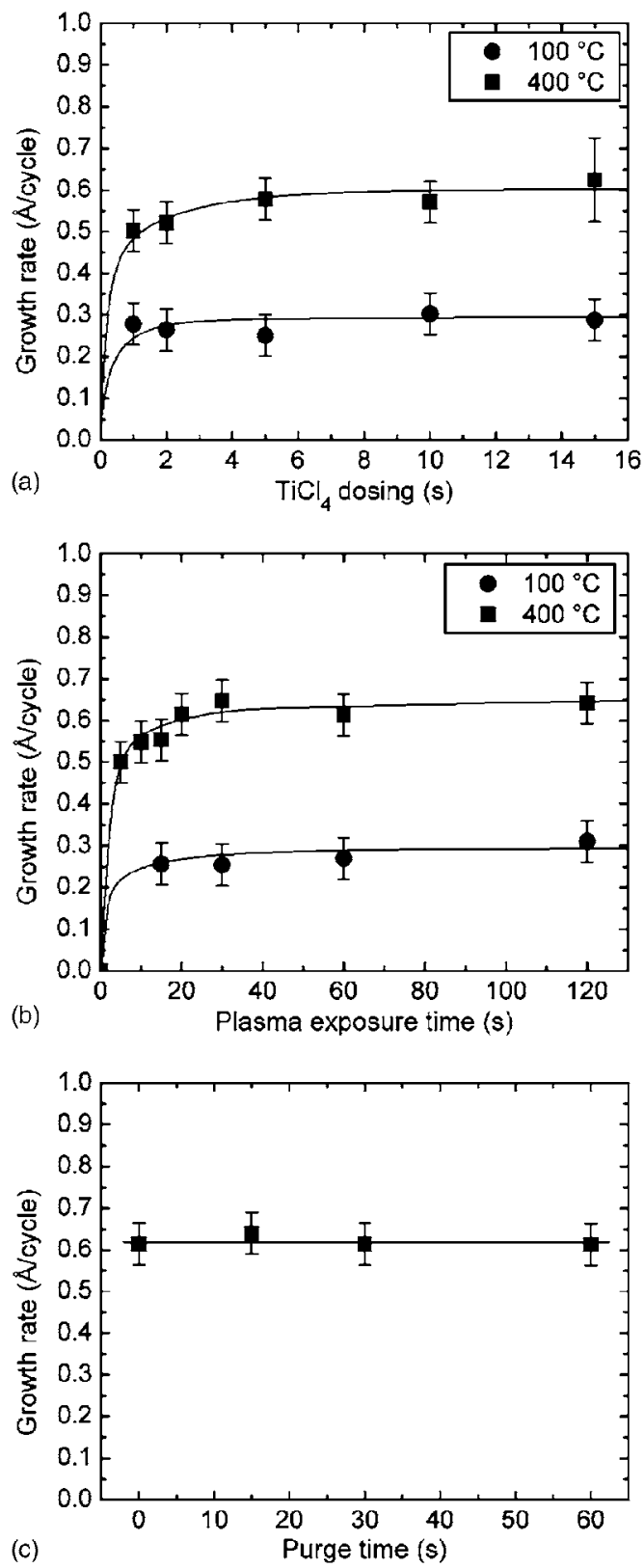

Figure 4. Growth rate per cycle as a function of (a) the $\mathrm{TiCl}_{4}$ precursor dosing, (b) the $\mathrm{H}_{2}-\mathrm{N}_{2}$ plasma exposure time, and (c) the Ar purge time in between the precursor and the plasma step. Other deposition conditions were kept constant at their base values (see Table I). Data are given for a substrate temperature of 100 and $400^{\circ} \mathrm{C}$. The lines serve as guides to the eyes.

obtained for a $45 \mathrm{~nm}$ thick film when using a longer plasma exposure time of $30 \mathrm{~s}$. At a deposition temperature of $400^{\circ} \mathrm{C}$ the $\mathrm{Cl}$ content in the layer was even found to decrease to 0.07 atom \%, which is close to the detection limit of RBS. The H content of the films increases at lower substrate temperatures and longer plasma exposure times, and was as high as 16 atom $\%$ for the $45 \mathrm{~nm}$ thick film deposited at $100^{\circ} \mathrm{C}$.

Structural properties. - Insight into the structural properties of the PA-ALD TiN films was obtained from XRD and AFM measure-

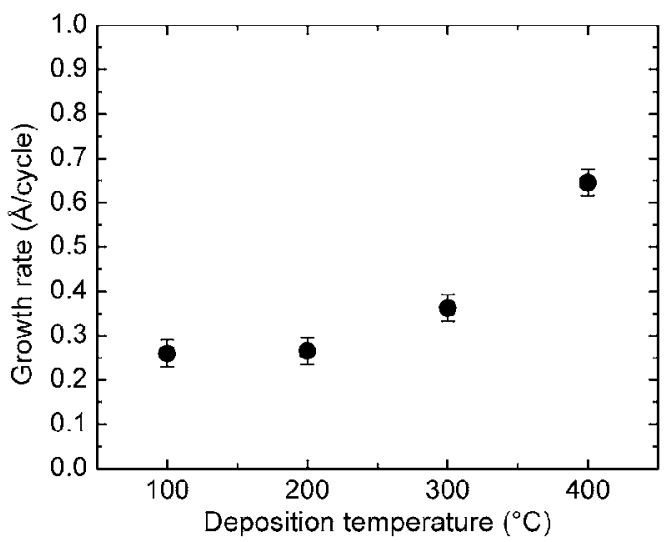

Figure 5. Growth rate per cycle as a function of deposition temperature as determined by in situ spectroscopic ellipsometry (SE).

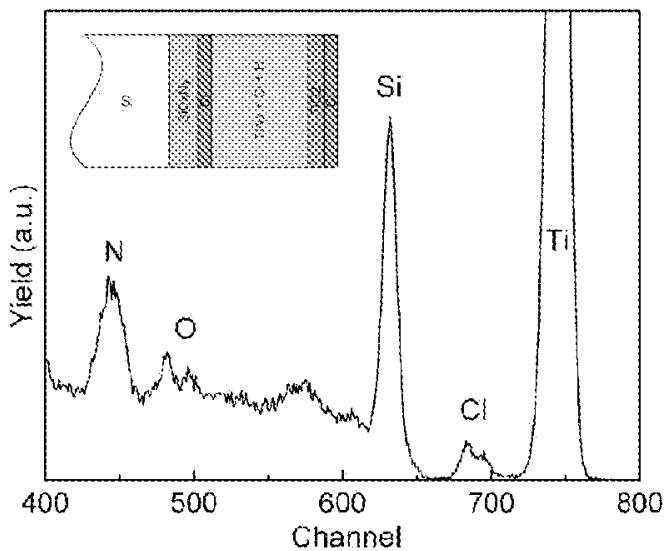

Figure 6. (Color online) RBS spectrum of a $11 \mathrm{~nm}$ TiN film deposited on a Si substrate. The inset shows the stacked-layer model which was used for fitting the RBS spectrum.

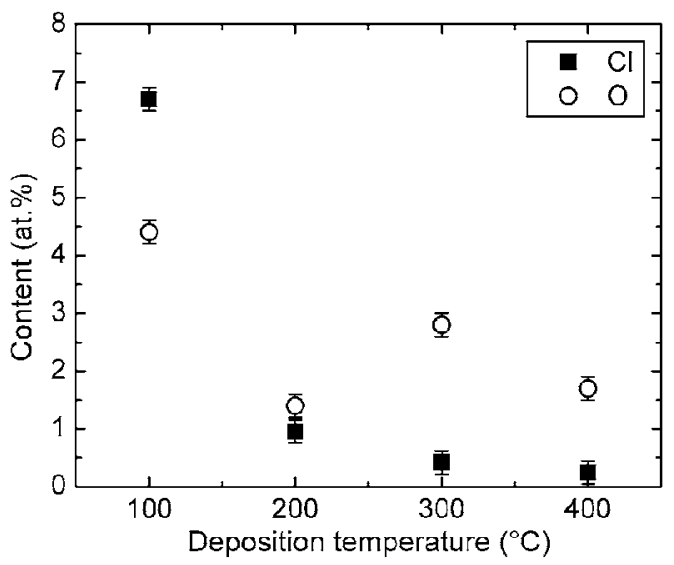

Figure 7. Chlorine and oxygen impurity contents in the TiN films, expressed in atomic percentages, as a function of deposition temperature. 

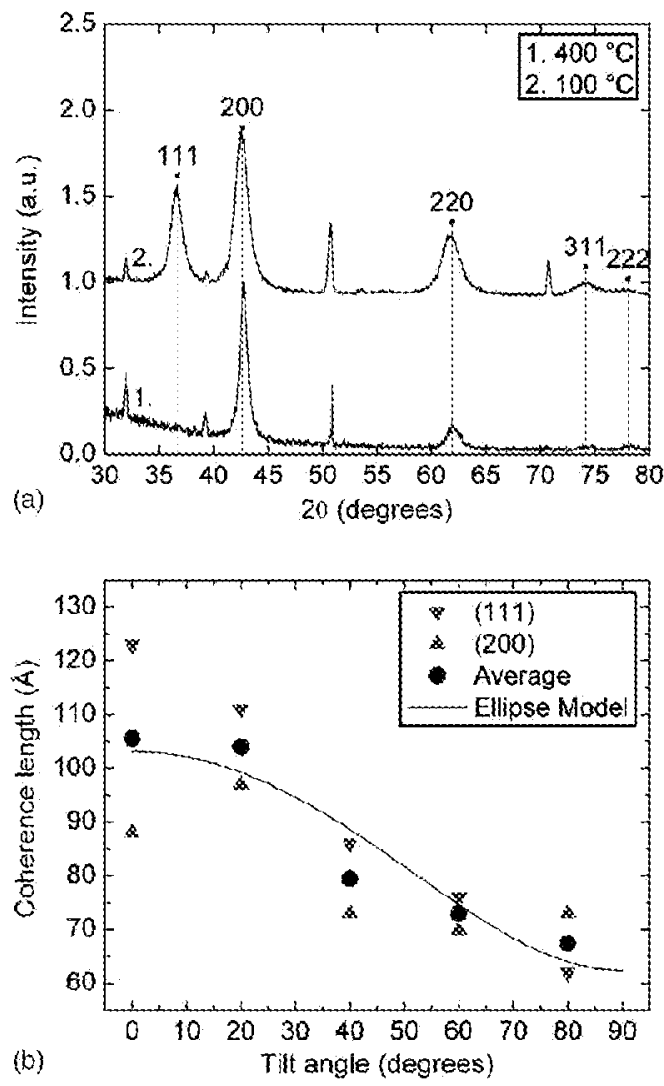

Figure 8. (Color online) (a) Microstructure of TiN films deposited at 100 and $400^{\circ} \mathrm{C}$ as determined with grazing incidence XRD. The different diffraction peaks for TiN are assigned in the figure. The other peaks originate from the crystalline silicon substrate. (b) Coherence length calculated from the width of the (111) and (200) diffraction peaks at different tilt angles using Scherrer's equation. The average is fitted by an ellipse model to determine the perpendicular and lateral grain dimensions.

ments yielding the microstructure and morphology of the films, respectively. The density of the films was calculated from a fit of $\mathrm{X}$-ray reflectometry (XRR) data.

The microstructure of the films was studied for films with a thickness larger than $45 \mathrm{~nm}$. The XRD spectra in Fig. 8a show a clear difference in microstructure between TiN films deposited at 100 and at $400^{\circ} \mathrm{C}$. Although both films are polycrystalline, a (200) preferential growth direction is found for $400^{\circ} \mathrm{C}$, whereas the $100^{\circ} \mathrm{C}$ film is merely randomly oriented. For the film deposited at $100^{\circ} \mathrm{C}$ the grain size was determined in both in lateral and parallel direction to the substrate normal by measuring an XRD spectrum at different angles. In Fig. 8b the coherence length calculated from the width of the peaks using Scherrer's equation is shown as a function of the angle. The grain size could be determined for this sample assuming an elliptical shape of the grains. The width (defined lateral to the surface) and the length (defined parallel to substrate normal) of the grains in this $45 \mathrm{~nm}$ thick film were found to be $\sim 6$ and $\sim 10 \mathrm{~nm}$, respectively. Besides the grain size also the orientation of the grains was determined by making a so-called polar plot with the XRD. It was found that the film has a textured structure with (200) being the preferred crystallographic orientation, i.e., there is a preference for the (200) axis of orientation to be parallel with the direction of the substrate normal. These structural properties can have influences on both conductivity and the barrier properties of the TiN. Diffusion along grain boundaries is suggested to be one of the main causes of diffusion barrier failure.

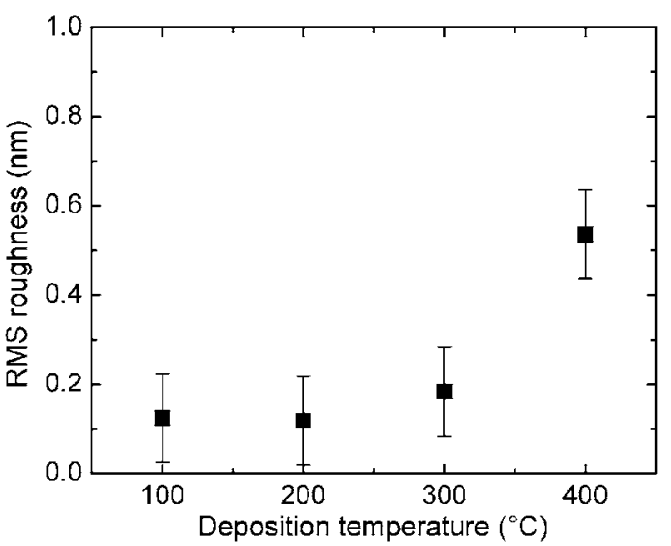

Figure 9. Root-mean-square (rms) roughness as determined with AFM for TiN films deposited on native oxide covered substrates.

The density of the TiN films is also significantly affected by the deposition temperature; for 100 and $400^{\circ} \mathrm{C}$ the film density was 3.7 and $4.8 \mathrm{~g} \mathrm{~cm}^{-3}$, respectively. This difference in density can be partly attributed to the increase in hydrogen content from 3 atom $\%$ at $400^{\circ} \mathrm{C}$ to 16 atom $\%$ at $100^{\circ} \mathrm{C}$. Others have reported densities as low as $3.5 \mathrm{~g} \mathrm{~cm}^{-3}$ for films deposited in the same temperature range by metallorganic ALD ${ }^{26}$ and most chemical deposition techniques report density values significantly lower than the TiN bulk density of $5.43 \mathrm{~g} \mathrm{~cm}^{-3}$. The density obtained by PA-ALD could possibly be enhanced by using additional ion bombardment, for example by external biasing of the substrate holder.

A plot of the surface roughness as a function of the deposition temperature is given in Fig. 9. The measured roughness of $0.1 \mathrm{~nm}$ for the low-temperature samples is close to the detection limit of this AFM and close to the surface roughness of the substrate surface prior to deposition. From the figure, the roughness seems to increase with the substrate temperature. However, the samples were deposited using the same number of cycles and, because the growth rate varies with temperature, the thickness of the films varies from 6 to $12 \mathrm{~nm}$. When comparing the roughness data for thin and thick films as given in Table II, it turns out that the roughness of the $100^{\circ} \mathrm{C}$ samples increases considerably with film thickness. The roughness of the $400^{\circ} \mathrm{C}$ sample seems to remain constant at the same value as for the $12 \mathrm{~nm}$ thickness. No significant differences in surface roughness for films deposited on native oxide covered silicon and $\mathrm{HF}$ last silicon substrates were observed.

Electrical properties. - The resistivity of the thin films $(6-12 \mathrm{~nm})$ was determined in situ by modeling the spectroscopic ellipsometry data with the Drude-Lorentz oscillator parameterization. ${ }^{21,22}$ The resistivity values were corrected to their room-temperature values using the intrinsic temperature dependence of the TiN determined in a calibration measurement. The resistivity was also determined ex situ from four-point probe measurements. The results are shown in Fig. 10. For deposition temperatures of $200^{\circ} \mathrm{C}$ and higher both methods are in good agreement. At $100^{\circ} \mathrm{C}$, a resistivity of $310 \mu \Omega \mathrm{cm}$ is obtained from the Drude term in the ellipsometry model prior to exposure of the sample to the ambient, and this value is significantly lower than the four-point probe value. This difference can partly be attributed to postoxidation of the $6 \mathrm{~nm}$ film as seen from the RBS analysis. Additionally, other impurities such as $\mathrm{Cl}$ and $\mathrm{H}$ as well as the microstructure will have an influence on the resistivity. It is clearly observed that the resistivity of the TiN films increases when the $\mathrm{Cl}$ content also increases. Also, the nonstoichiometric films appear to have a somewhat higher resistivity, as has also been observed for sputtered TiN films. ${ }^{27}$ The best resisitivity values were 


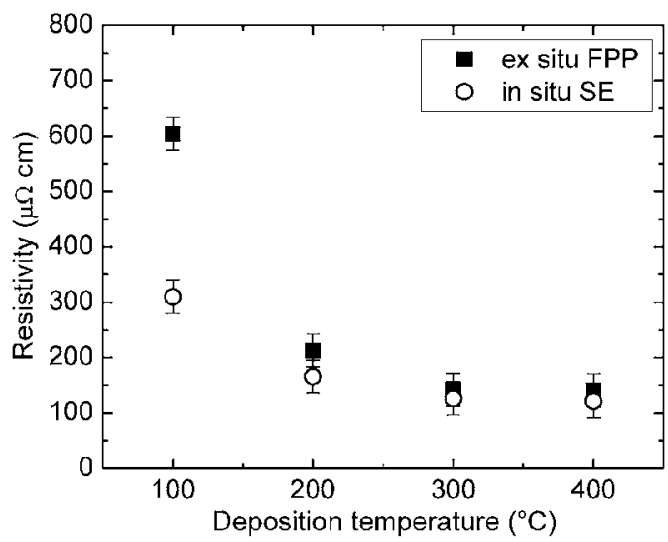

Figure 10. Resistivity of the TiN films as a function of deposition temperature as determined in situ by SE and ex situ by four-point probe (FPP) measurements. The values obtained in situ have been corrected to represent room-temperature values using the intrinsic temperature dependence of the resistivity of the TiN films.

obtained for the thick films ( $>45 \mathrm{~nm}$, using the 4-point probe): 209 and $71 \mu \Omega \mathrm{cm}$ at deposition temperatures of 100 and $400^{\circ} \mathrm{C}$, respectively.

\section{Discussion}

In this section, we discuss the PA-ALD TiN process and compare it to other ALD and PA-ALD processes for TiN deposition as reported. An overview of these processes is given in Table III, in which the results on growth rate per cycle, impurity content, resistivity, and morphology of the films are summarized.

Although similar values have been reported by others, ${ }^{7}$ the deposition rate at $400^{\circ} \mathrm{C}$ is higher than often reported for ALD and PAALD of TiN. We attribute this difference to the strong temperature dependence of the growth rate per cycle. The growth rate increases sharply between 350 and $400^{\circ} \mathrm{C}$, where most experiments are con- ducted. A slight difference in the setpoint temperature or actual temperature of the wafer could explain the differences in literature values. The heat load coming from the impinging ions during the plasma step, $\sim 6 \times 10^{-4} \mathrm{~W} \mathrm{~cm}^{-2}$, can be considered negligible compared to heating provided by the substrate heater. The reason why the deposition rate increases with deposition temperature is not yet well understood. Possible causes are suggested to be the removal process of surface $\mathrm{Cl}$ being thermally activated, but this is not supported by data presented by Kim et al., ${ }^{13}$ and the nature or reactivity of the surface species $\left(\mathrm{NH}_{x}\right)$ created after the plasma step varying with temperature. In this work it is however clearly established that both at 100 and $400^{\circ} \mathrm{C}$ the growth process is purely ALD.

It was also established that the investigated PA-ALD process yields good material properties at high temperatures (at $400^{\circ} \mathrm{C}$ ) in terms of a low impurity content $(0.07$ atom $\% \mathrm{Cl})$ and low resistivity $(71 \mu \Omega \mathrm{cm})$. These results are among the best reported for an ALD process of TiN. ${ }^{7,28}$ Only a $\mathrm{TiCl}_{4}+\mathrm{Zn}$ and $\mathrm{NH}_{3}$ process gave slightly better results, but that process is not compatible with current $\mathrm{Si}$ wafer technology ${ }^{29} \mathrm{TiI}_{4}$ was tried as an alternative metal-halide source for Ti in combination with $\mathrm{NH}_{3}$ and, although it resulted in a lower inclusion of halide impurities, the growth rate was low at $400^{\circ} \mathrm{C}{ }^{30}$ In an attempt to lower $\mathrm{Cl}$ impurities, different sources for nitrogen have also been studied for the thermal metal-halide ALD process, such as allylamine and butylamine, ${ }^{31}$ or dimethylhydrazine. ${ }^{32}$ Yet they did not yield better material properties and generally led to lower growth rates.

We showed that, with the assistance of a plasma step, TiN films can be deposited with reasonably good material properties at low temperatures. The best values at a deposition temperature of $100^{\circ} \mathrm{C}$ were found for a relatively thick TiN film of $45 \mathrm{~nm}$. A reasonable low $\mathrm{Cl}$ impurity content of 2.1 atom $\%$ and a low resistivity of $209 \mu \Omega \mathrm{cm}$ were obtained. However, it was also found that the material properties improve significantly when going to temperatures around $200^{\circ} \mathrm{C}$. Halide-free films can be deposited at low temperatures $\left(50-250^{\circ} \mathrm{C}\right)$ using metallorganic compound precursors such as tetrakis-dimethyl-amino-titanium (TDMAT), tetrakisdiethyl-amino-titanium (TDEAT), ${ }^{26}$ or tetrakis-ethylmethyl-aminotitanium (TEMAT) ${ }^{33}$ in combination with $\mathrm{NH}_{3}$, referred to as MO-

\begin{tabular}{|c|c|c|c|c|c|c|c|c|c|}
\hline \multicolumn{2}{|c|}{ Deposition type } & \multirow{2}{*}{$\frac{\text { Precursors }}{\mathrm{TiCl}_{4}+\mathrm{NH}_{3}}$} & \multirow{2}{*}{$\frac{{ }^{\circ} \mathrm{C}}{400}$} & \multirow{2}{*}{$\begin{array}{c}\begin{array}{c}\text { Growth rate } \\
\AA / c y c l e\end{array} \\
0.6\end{array}$} & \multirow{2}{*}{$\begin{array}{c}\begin{array}{c}\text { C-content } \\
\text { atom } \%\end{array} \\
-\end{array}$} & \multirow{2}{*}{$\begin{array}{l}\begin{array}{c}\text { Cl-content } \\
\text { atom } \%\end{array} \\
0.4\end{array}$} & \multirow{2}{*}{$\begin{array}{c}\begin{array}{c}\text { Resistivity } \\
{[1] \mathrm{cm}}\end{array} \\
440\end{array}$} & \multirow{2}{*}{$\frac{\text { Morphology }}{\text { polycrystalline }}$} & \multirow{2}{*}{$\frac{\text { Reference }}{7}$} \\
\hline Thermal & MH-ALD & & & & & & & & \\
\hline & & $\mathrm{TiCl}_{4}+\mathrm{NH}_{3}$ & 350 & 0.4 & - & 2.5 & 350 & polycrystalline & 28 \\
\hline & & $\mathrm{TiCl}_{4}+\mathrm{Zn}+\mathrm{NH}_{3}$ & 500 & 0.2 & - & $0.01-0.04$ & 50 & polycrystalline & 29 \\
\hline & & $\mathrm{Til}_{4}+\mathrm{NH}_{3}$ & 400 & 0.12 & - & $0.5^{\mathrm{a}}$ & 380 & polycrystalline & 30 \\
\hline & & $\mathrm{TiCl}_{4}+\underset{\text { (allylamine) }}{\mathrm{CH}_{3}=\mathrm{CHCH}_{2} \mathrm{NH}}$ & 400 & 0.15 & $<1$ & 7 & 360 & weakly crystalline & 31 \\
\hline & & $\begin{array}{l}\mathrm{TiCl}_{4}+\left(\mathrm{CH}_{3}\right)_{3} \mathrm{CNH}_{2} \\
\text { (butylamine) }\end{array}$ & 400 & 0.03 & 9 & 1.4 & 310 & weakly crystalline & 31 \\
\hline & & $\begin{array}{c}\mathrm{TiCl}_{4}+\left(\mathrm{CH}_{3}\right)_{2} \mathrm{NNH}_{2} \\
\text { (dimethylhydrazine) }\end{array}$ & 200 & 0.11 & - & 23 & $>3000$ & amorphous & 32 \\
\hline & & & 400 & 0.26 & - & 2 & 650 & polycrystalline & 32 \\
\hline & MO-ALD & $\mathrm{TDMAT}+\mathrm{NH}_{3}$ & 200 & 5 & 25 & - & 600 & amorphous & 26 \\
\hline & & TDEAT $+\mathrm{NH}_{3}$ & 200 & 1 & 20 & - & 1000 & amorphous & 26 \\
\hline & & TEMAT $+\mathrm{NH}_{3}$ & 200 & 5 & $<4$ & - & - & - & 33 \\
\hline \multirow[t]{8}{*}{ Plasma } & MH-ALD & $\mathrm{TiCl}_{4}+\mathrm{Ar} / \mathrm{H}_{2} / \mathrm{N}_{2}$ plasma & 350 & 0.46 & - & $<0.6$ & 80 & polycrystalline & 25 \\
\hline & & $\mathrm{TiCl}_{4}+\mathrm{H}_{2} / \mathrm{N}_{2}$ plasma & 320 & 0.3 & & 6 & 150 & polycrystalline & 12 \\
\hline & & $\mathrm{TiCl}_{4}+\mathrm{H}_{2} / \mathrm{N}_{2}$ plasma & 100 & 0.26 & - & 2.1 & 210 & polycrystalline & this work \\
\hline & & & 400 & 0.6 & - & 0.07 & 72 & polycrystalline & this work \\
\hline & MO-ALD & TDMAT $+\mathrm{H}_{2}$ & 200 & 4 & 15 & - & 600 & polycrystalline & 36 \\
\hline & & TDMAT $+\mathrm{H}_{2} / \mathrm{N}_{2}$ & 200 & 4 & 13 & - & 580 & polycrystalline & 36 \\
\hline & & $\mathrm{TDMAT}+\mathrm{N}_{2}$ & 200 & 4 & 4 & - & 250 & polycrystalline & 35 and 37 \\
\hline & & $\mathrm{TDMAT}+\mathrm{NH}_{3}$ & 200 & - & 1 & - & 1500 & - & 37 \\
\hline
\end{tabular}

${ }^{\text {a }}$ l-content instead of Cl-content. 
ALD. The advantages of MO-ALD are higher growth rates and the fact that the films are reported to be amorphous, which is suggested to form a better diffusion barrier. The metal-organic compounds have, however, a poor thermal stability and decompose readily during deposition. ${ }^{34}$ The deposited films were found to have a low density and a relatively high resistivity due to a high carbon content.

A PA-ALD process using a metal-halide precursor such as $\mathrm{TiCl}_{4}$ is therefore a good alternative for MO-ALD in the case that a low C contamination can be allowed. The $\mathrm{Cl}$ impurity is probably not detrimental when working at temperatures below $250^{\circ} \mathrm{C}$, and the PAALD process reported can therefore be of interest for several applications of ALD TiN films.

The fact that we obtained reasonable to very good quality ALD TiN films both at high and low temperatures can be attributed to the reactive species, such as $\mathrm{H}$ and $\mathrm{N}$ radicals, that are formed in the plasma independently of the deposition temperature. These radicals facilitate surface chemical reactions to occur at lower deposition temperatures. However, also the ion flux toward the substrate during the plasma exposure step cannot be neglected. The ion flux of $\sim 2.5 \times 10^{14} \mathrm{~cm}^{-2} \mathrm{~s}^{-1}$ is quite significant during the plasma exposure of $15 \mathrm{~s}$, yielding $\sim 4 \times 10^{15}$ ions $\mathrm{cm}^{-2}$ arriving at the surface during every cycle. This flux is equivalent to a few monolayers of ions per cycle, while a growth rate of $0.4 \AA /$ cycle corresponds roughly with one-third monolayer per cycle. Every ion brings roughly $15 \mathrm{eV}$ of energy to the film without actually heating the substrate, and at impact this kinetic energy can be used for enhancing surface reactions such as $\mathrm{Cl}$ removal or for densifying the material. The ions can also induce substrate modification such as the formation of the $\operatorname{SiN}_{x} \mathrm{O}_{y}$ layer, as mentioned before. Significant plasma damage is however not expected because the ion energy is relatively low, and lower than typical threshold energies for creating defect sites or for sputtering.

In view of the above, PA-ALD with metallorganics is also very interesting as it should have similar benefits provided by the plasma step. The investigations reported so far used plasmas generated with different mixtures of $\mathrm{H}_{2}-\mathrm{N}_{2},{ }^{35,36}$ and recently also with $\mathrm{NH}_{3} \cdot{ }^{37}$ The best results in terms of resistivity, $250 \mu \Omega \mathrm{cm}$, and $\mathrm{C}$ impurity content, 4 atom \% were obtained with TDMAT and a pure $\mathrm{N}_{2}$ plasma. The advantage of the higher growth rate for PA-ALD with metal organics, however, has not yet surpassed the low resistivity achieved in this work by PA-ALD with $\mathrm{TiCl}_{4}$.

\section{Conclusions}

A PA-ALD process for the deposition of $\mathrm{TiN}$ using $\mathrm{TiCl}_{4}$ as precursor in combination with a $\mathrm{H}_{2}-\mathrm{N}_{2}$ plasma in the temperature range of 100 to $400^{\circ} \mathrm{C}$ was presented. The plasma studies were carried out using OES and Langmuir probe measurements, revealing basic insight into the plasma species and their dependence on the operating conditions. An important result is that the plasma just above the substrate can still be qualified as an active plasma with a fairly high electron density and electron temperature. From these measurements it was concluded that there is a considerable ion flux toward the substrate per ALD cycle with an average ion energy of roughly $15 \mathrm{eV}$. The growth rate per cycle was investigated by in situ spectroscopic ellipsometry to explore the conditions under which the surface reactions are self-limiting. These investigations were carried out for a deposition temperature of 100 and $400^{\circ} \mathrm{C}$ and revealed pure ALD growth for the complete temperature range. Furthermore, it was established that the TiN growth rate per cycle has a fairly strong temperature dependence. The film properties of the PA-ALD TiN films were extensively characterized by techniques such as RBS, ERD, XRD, XRR, AFM, spectroscopic ellipsometry, and fourpoint probe measurements. These measurements revealed that the PA-ALD TiN process yields good quality ALD TiN films at high temperatures, but that especially the films deposited at $100^{\circ} \mathrm{C}$ have a reasonably good quality in terms of impurity content $(2.1$ atom \%) and resistivity $(209 \mu \Omega \mathrm{cm})$ compared to other alternative low-temperature ALD techniques.
PA-ALD of TiN using a combination of $\mathrm{TiCl}_{4}$ precursor dosing and $\mathrm{H}_{2}-\mathrm{N}_{2}$ plasma exposure has therefore great potential for applications requiring low deposition temperatures. In future work, therefore, apart from the more mainstream applications in CMOS and DRAM, there will be a strong focus on applications with stricter demands on thermal budget such as sensor and microsystem technology and 3D-integration passive and active components in stacked die structures. In these studies also the conformality or step coverage of the process will be investigated in detail when the deposition of the TiN in high-aspect ratio structures needs to be considered.

\section{Acknowledgments}

The RBS analysis was performed by Y. Tamminga and T. Dao and the XRD measurements by $\mathrm{F}$. Bakker and $\mathrm{H}$. Wondergem (all Philips Research, Eindhoven). The authors would like to thank A. Rahtu of ASM Microchemistry for the XRR density calculations and J. Klootwijk of Philips for his assistance with the electrical characterization. M. J. F. van de Sande, J. Jansen, A. B. M. Hüsken, and H. M. M. de Jong are acknowledged for their skillful technical assistance. This work was supported by the Dutch Technology Foundation STW. The research of W. K. was made possible by a fellowship from the Royal Netherlands Academy of Arts and Sciences (KNAW).

Eindhoven University of Technology assisted in meeting the publication costs of this article.

\section{References}

1. P. Mărtensson, M. Juppo, M. Ritala, M. Leskelä, and J.-O. Carlsson, J. Vac. Sci. Technol. B, 17, 2122 (1999).

S. Smith, W.-M. Li, K.-E. Elers, and K. Pfeifer, Microelectron. Eng., 64, 247 (2002).

3. D.-J. Kim, Y.-B. Jung, M.-B. Lee, Y.-H. Lee, J.-H. Lee, and J.-H. Lee, Thin Solid Films, 372, 276 (2000).

4. F. Fillot, T. Morel, S. Minoret, I. Matko, S. Maîtrejean, B. Guillaumot, B. Chenevier, and T. Billon, Microelectron. Eng., 82, 248 (2005).

5. J. K. Schaeffer, S. B. Samavedam, D. C. Gilmer, V. Dhandapani, P. J. Tobin, J. Mogab, B.-Y. Nguyen, B. E. White, Jr., S. Dakshina-Murthy, R. S. Rai, Z.-X. Jiang, R. Martin, M. V. Raymond, M. Zavala, L. B. La, J. A. Smith, R. Garcia, D. Roan, M. Kottke, and R. B. Gregory, J. Vac. Sci. Technol. B, 21, 11 (2003).

6. D.-G. Park, K.-Y. Lim, H.-J. Cho, T.-H. Cha, I.-S. Yeo, J.-S. Roh, and J. W. Park, Appl. Plys. Lett., 80, 2514 (2002).

7. J. Kim, H. Hong, S. Ghosh, K.-Y. Oh, and C. Lee, Jpn. J. Appl. Phys., Part 1, 42, 1375 (2003).

8. K.-E. Elers, V. Saanila, P. J. Soininen, W.-M. Li, J. T. Kostamo, S. Haukka, J. Juhanoja, and W. F. A. Besling, Chem. Vap. Deposition, 8, 149 (2002).

M. Moriwaki and T. Yamada, Jpn. J. Appl. Phys., Part 1, 40, 2679 (2001)

9. M. Moriwaki and T. Yamada, Jpn. J. Appl. Phys., Part 1, 40, $2679(2001)$.
10. S. M. Rossnagel, A. Sherman, and F. Turner, J. Vac. Sci. Technol. B, 18, 2016 (2000).

11. S. B. S. Heil, E. Langereis, A. Kemmeren, F. Roozeboom, M. C. M. van de Sanden, and W. M. M. Kessels, J. Vac. Sci. Technol. A, 23, L5 (2005).

12. K. -E. Elers, J. Winkler, K. Weeks, and S. Marcus, J. Electrochem. Soc., 152 , G589 (2005).

13. H. Kim and S. M. Rossnagel, J. Vac. Sci. Technol. A, 20, 802 (2002).

14. F. Greer, D. Fraser, J. W. Coburn, and D. B. Graves, J. Vac. Sci. Technol. A, 21, 96 (2003).

15. E. Gerritsen, N. Emonet, C. Cailat, N. Jourdan, M. Piazza, D. Fraboulet, B. Boeck, A. Berthelot, S. Smith, and P. Mazoyer, Solid-State Electron., 49, 1767 (2005).

16. P. Jain and E. J. Rymaszewski, Thin-Film Capacitors for Packaged Electronics, Kluwer Academic Publishers, Dordrecht (2004).

17. F. Roozeboom, A. L. A. M. Kemmeren, J. F. C. Verhoeven, F. C. van den Heuvel, J. Klootwijk, H. Kretschman, T. Frič, E. C. E. van Grunsven, S. Bardy, C. Bunel, D. Chevrie, F. LeCornec, S. Ledain, F. Murray, and P. Philippe, Thin Solid Films,

18. S. B. S. Heil, E. Langereis, A. Kemmeren, F. Roozeboom, N. P. Pham, P. M. Sarro, M. C. M. van de Sanden, and W. M. M. Kessels, Mater. Res. Soc. Symp. Proc., 863, B6.4.1 (2005)

19. E. W. Peterson and L. Talbot, ALAA J., 8, 2215 (1970).

20. H. G. Tompkins and W. A. McGahan, Spectroscopic Ellipsometry and Reflectometry: A User's Guide, John Wiley and Sons Inc., New York (1999).

21. E. Langereis, S. B. S. Heil, M. C. M. van de Sanden, and W. M. M. Kessels, Phys. Status Solidi C, 2, 3958 (2005).

22. E. Langereis, S. B. S. Heil, M. C. M. van de Sanden, and W. M. M. Kessels, J. Appl. Phys., 100, 023534 (2006)

23. L. Doolittle, Nucl. Instrum. Methods Phys. Res. B, 9, 344 (1985).

24. M. A. Lieberman and A. J. Lichtenberg, Principles of Plasma Discharges and Materials Processing, John Wiley \& Sons Inc., New York (1994).

25. Y. J. Lee and S.W. Kang, J. Vac. Sci. Technol A 21, L13 (2003).

26. J. Y. Kim, G. H. Choi, Y. D. Kim, Y. Kim, and H. Jeon, Jpn. J. Appl. Phys., Part $1,42,4245$ (2003). 
27. J. H. Kang and K. J. Kim, J. Appl. Phys., 86, 346 (1999).

28. H. Jeon, J.-W. Lee, Y.-D. Kim, D.-S. Kim, and K.-S. Yi, J. Vac. Sci. Technol. A, 18, $1595(2000)$.

9. M. Ritala, T. Asikainen, M. Leskelä, J. Jokinne, R. Lappalainen, M. Utrainen, I. Niinistö, and E. Ristolainen, Appl. Surf. Sci., 120, 199 (1997).

30. M. Ritala, M. Leskelä, E. Rauhala, and I. Jokinen, J. Electrochem Soc, 145, 2914 (1998).

31. M. Juppo, P. Alén, M. Ritala, T. Sajavaara, J. Keinonen, and M. Leskelä, Electrochem. Solid-State Lett., 5, C4 (2002).

32. M. Juppo, M. Ritala, and M. Leskelä, J. Electrochem. Soc., 147, 3377 (2000).
33. J.-S. Min, Y.-W. Son, W.-G. Kang, and S.-W. Kang, Jpn. J. Appl. Phys., Part I, 37, 4999 (1998).

34. J. W. Elam, M. Schuisky, J. D. Ferguson, and S. M. George, Thin Solid Films, 436 145 (2003).

35. J. Y. Kim, Y. Kim, and H. Jeon, Jpn. J. Appl. Phys., Part 2, 42, L414 (2003).

36. J. Y. Kim, S. Seo, D. Y. Kim, H. Jeon, and Y. Kim, J. Vac. Sci. Technol. A, 22, 8 (2004).

37. J. Y. Kim, D. Y. Kim, H. O. Park, and H. Jeon, J. Electrochem. Soc., 152, G29 (2005). 